\title{
Constraints Pertaining to Fenugreek (Trigonella corniculata) Production Technology in Rajasthan, India
}

\author{
S.R. Kumawat ${ }^{1}$, U.B. Singh ${ }^{2}$ and P.S. Bagenia ${ }^{2^{*}}$ \\ ${ }^{1}$ KVK Nagaur, Agriculture University, Jodhpur, India \\ ${ }^{2}$ ARSS, Kumher, Bharatpur (SKNAU, Jobner), India \\ *Corresponding author
}

\begin{tabular}{|l|}
\hline K ey w or d s \\
$\begin{array}{l}\text { Fenugreek } \\
\text { (Trigonella } \\
\text { corniculata), Home } \\
\text { of spices }\end{array}$ \\
\hline Article Info \\
\hline $\begin{array}{l}\text { Accepted: } \\
\text { 24 September } 2018 \\
\text { Available Online: } \\
\text { 10 October } 2018\end{array}$ \\
\hline
\end{tabular}

\section{A B S T R A C T}

India has been the home of spices since time immemorial. It is the world largest producer, consumer and exporter of seed spices which are being cultivated widely in the country over different agro- climatic zones. Fenugreek is an important seed spices crop of Rajasthan. It is cultivated more than 1.57 lac hectare area with production of 1.9 lac tonnes. Major fenugreek growing districts of Rajasthan are Bikaner, Jodhpur, Churu, Sikar, jhunjhunu and Nagaur. This study was conducted in Nagaur district of Rajasthan in the year 2013-14 to know the adoption level of fenugreek growers and to ascertain the causes for low adoption of fenugreek (pan methi) production technology. A sample of 120 respondents was proportionate randomly selected for the study. A schedule was used to investigate adoption level as well as reasons responsible for low adoption being faced by the respondent in adoption of fenugreek technology. The study revealed that an appreciable level of adoption was found in irrigation management, soil and land preparation and taking seed yield from crop under high level category. The five major constraints were included in the study i.e. input, financial, marketing, technical and general constraints. Among these constraints, marketing constraints was reported as the most important which affects the adoption of fenugreek cultivation stood rank first followed by general constraints, technical constraints, input, constraints were perceived by the respondents and placed rank second, third and fourth, respectively however financial constraints were faced as least important by the respondents in adoption of fenugreek production technology.

\section{Introduction}

India has been the 'Home of Spices' since time immemorial. It is the world largest producer, consumer and exporter of seed spices which are being cultivated widely in the country over different agro-climatic zones. Seed species crop occupy, prominent place in the total basket of spices of the country and play a significant role in our national economy. The group of spices account for about 37 per cent and 18 per cent of the total area and production of spices in the country, respectively. The production of fenugreek (Panmethi) in India in marked by its dominants position in the world production and export from India. About 99 percent production of fenugreek is produced by 
Rajasthan alone. The fenugreek plant is an annual herbaceous forage legume with aroma which is used for food in the form of its seeds as spices and its leaves as vegetables.

Panmethi / (Trigonella corniculata) is an important seed-spices crop of Rajasthan, it comes under scented group (Kasuri methi) of fenugreek. It is cultivated in more than 1.57 lac hectare area with production of 1.9 lac tone (2015-16). Major fenugreek producing districts of Rajasthan are Bikaner, Jodhpur, Churu, Sikar, Jhunjunu and Nagaur. In Rajasthan only in Nagaur district it is cultivated in the name of pan methi because only leaves are harvested four to five times during crop season, after drying of leaves it is used as a food flavouring agent of food preparation. Therefore keeping this view in mind a study had been undertaken with the following specific objectives to study the extent of adoption of improved fenugreek cultivation by the farmers to ascertain the constraint perceived by the farmers in adoption of fenugreek production technology at Nagaur district of Rajasthan.

\section{Materials and Methods}

The present study was conducted in Nagaur district of Rajasthan due to having maximum area under pan methi cultivation as well as main exporter in the state. The district comprises 12 panchayat samities. Out of which two panchayat samities were purposely selected on the basis of maximum area under pan methi cultivation in the districts. Similarly 4 panchayats were selected on the basis of maximum area of this crop among panchayats and three villages from each panchayat were selected randomly hence total 24 villages were included in the study. To select respondents, a comprehensive list of all the fenugreek growers who were growing fenugreek crop for last 5 years was so prepared with the help of revenue patwari and concern agricultural supervisor. Then a proportionate sample from each parchayat was drawn randomly to have a total sample size of 120 fenugreek growers for the study.

With a view to find out the extent of adoption of recommended production technology of fenugreek cultivation. The respondent were ask to give their responses about production technology adopted them to find out the extent of adoption of production technology of fenugreek by using adoption index developed by singh (2009) with slightly modification. To set a logical view of the respondents, they were classified into three categories i.e. low, medium and high on the basis of mean and standard deviation. To explore the technology wise extent of adoption of improved production technology of fenugreek (pan methi). Fourteen technologies of pan methi cultivation scrutinized by expert were considered. The practice wise score were assigned to each adoption practice making a total 100. On the basis of practice wise adoption scores obtained by the respondents. The mean percent score (MPS) were worked out for the technologies of improved pan methi cultivation by the cultivators.

In the present study, the term constraint means the barriers, obstacles, hindrance or causes which are perceived by the respondents in adoption of fenugreek production technology. All possible constraints were included in the schedule in accordance with the fenugreek cultivation. The responses obtained from respondents were recorded on a three point continuum scale viz., very important, important and least important and were assigned score 3,2 and 1 respectively. The data thus, collected were classified, tabulated and analyzed in order to make the finding meaningful. The statistical measures, such as mean, standard deviation, Mean Percent Score (MPS) and rank order were used to analyze data. 


\section{Results and Discussion}

\section{Extent of adoption of improved fenugreek cultivation}

The level of adoption were measured in three category i.e. low, medium and high level of extent of adoption about fourteen selected technologies of improved fenugreek cultivation. It is apparent from Table 1. that the overall extent of adoption of improved production technologies of pan methi with MPS 33.54 Out of these selected technologies of the extent of adoption for irrigation management was found maximum with the 79.17 MPS followed by soil and land preparation (78.33 MPS), taking seed yield from crop (75.00 MPS) and drying of green leaves (73.33MPS) respectively, in case high level of adoption category, while in case of medium level of adoption, use of improved variety and seed treatment both are jointly having 58.33 MPS following by weed management (50.83MPS) measures and fertilizer management (48.33 MPS) and plant protection measures. The extent of adoption is under low level of category. Before marketing grading of leaves was found with maximum score 63.33MPS, whereas precautions against advance weather condition and plant protection measures were having score 49.17 and 35.00 MPS respectively. The findings conformity with the findings of Meena et al., (2002), Patel et al., (2004), Singh et al., (2010) and Singh et al., (2013)

Hence it may be inferred from the above result that the respondents were found very cautious about irrigation management, soil and land preparation, taking seed yield from crop and drying of green leaves for pan methi cultivation in the contrary they were least bothered about adoption of recommended application of culture (Rhizobuim and PSB) which has immense importance in safe guarding availability of atmospheric nitrogen fixation and increase the availability of phosphors from the soil to the pan methi crop ultimately, resulting very poor formation of nodules and availability of nitrogen from the environment in the plant resulting poor returns from the methi crop.

\section{Constraints faced by the farmers}

\section{Input constraints perceived by the farmers in adoption of recommended fenugreek production technology}

A critical examination of Table 2 revealed that majority of respondents were facing problems of "Unavailability of improved seed at time of sowing" (79.16 MPS) It was reported that majority of fenugreek cultivators are growing indigenous local selection of pan methi and other variety are not in trust of farmers.

It was followed by "Unavailability of labour at the time of picking of leaves" (75.00 MPS) and Unavailability of fertilizer at the peak seasons (70.83 MPS)" in adoption of recommended fenugreek production technology, "Requires more organic manure and gypsum for reclamation of soil" "Supply of inferior quality of seed by the input agencies" and lack of irrigation facility were ranked 4th, 5th and 6th respectively.

Data incorporated in Table 3 reveals that high cost of input (79.16 MPS) was perceived as the most important constraints with top priority by the majority of the respondents and accorded first rank because seed, fertilizers and insecticides, fungicides are costly in the market. Unavailability of credit on marginal interest (75.00 MPS) was another important problem faced by the fenugreek growers ranked this on second position. Lack of finance agencies (66.66 MPS) and High charges of electricity (51.66 MPS) emerged as third and fourth important problems perceived by the fenugreek growers. 
Table.1 Extent of adoption of improved fenugreek cultivation by the farmers

\begin{tabular}{|c|c|c|c|c|c|c|c|}
\hline \multirow{3}{*}{$\begin{array}{l}\text { S. } \\
\text { no. }\end{array}$} & \multirow[t]{3}{*}{ Improved practices } & \multicolumn{6}{|c|}{ Adoption level } \\
\hline & & \multicolumn{2}{|c|}{$\begin{array}{l}\text { Low score } \\
\text { before }(<33)\end{array}$} & \multicolumn{2}{|c|}{$\begin{array}{l}\text { Medium score } \\
\text { between (33-66) }\end{array}$} & \multicolumn{2}{|c|}{$\begin{array}{l}\text { High score } \\
\text { above }(>66)\end{array}$} \\
\hline & & No. & MPS & No. & MPS & No. & MPS \\
\hline 1. & Use of Improved variety seed & 20 & 16.67 & 70 & 58.33 & 30 & 25.00 \\
\hline 2. & Soil and land preparation & 6 & 5.00 & 20 & 16.67 & 94 & 78.33 \\
\hline 3. & Seed treatment & 22 & 18.33 & 70 & 58.33 & 28 & 23.33 \\
\hline 4. & Sowing method \& time & 18 & 15.00 & 18 & 15.00 & 84 & 70.00 \\
\hline 5. & $\begin{array}{l}\text { Manure and fertilizer } \\
\text { management }\end{array}$ & 12 & 10.00 & 58 & 48.33 & 50 & 41.67 \\
\hline 6. & Weed management & 9 & 7.50 & 61 & 50.83 & 50 & 41.67 \\
\hline 7. & Irrigation Management & 2 & 1.67 & 23 & 19.17 & 95 & 79.17 \\
\hline 8. & Plant protection measures & 42 & 35.00 & 58 & 48.33 & 20 & 16.67 \\
\hline 9. & $\begin{array}{l}\text { Precautions against adverse } \\
\text { weather condition }\end{array}$ & 59 & 49.17 & 42 & 35.00 & 19 & 15.83 \\
\hline 10. & $\begin{array}{l}\text { Picking management of green } \\
\text { leaves }\end{array}$ & 9 & 7.50 & 22 & 18.33 & 89 & 74.17 \\
\hline 11. & Drying of green leaves & 0 & 0.00 & 32 & 26.67 & 88 & 73.33 \\
\hline 12. & $\begin{array}{l}\text { Before marketing grading of } \\
\text { leaves }\end{array}$ & 76 & 63.33 & 28 & 23.33 & 16 & 13.33 \\
\hline 13. & Taking seed yield from crop & 12 & 10.00 & 28 & 23.33 & 90 & 75.00 \\
\hline \multirow[t]{4}{*}{14.} & Application of culture & 00 & 00 & 00 & 7.50 & 13 & 10.83 \\
\hline & total & 287 & 239.17 & 530 & 441.67 & 759 & 627.5 \\
\hline & Average & 22.0 & & & & 57.9 & \\
\hline & Overall MPS & & \multicolumn{5}{|c|}{33.54} \\
\hline
\end{tabular}

Table. 2 Constraints related to inputs supply as perceived by the fenugreek growers in adoption of Fenugreek cultivation technology $(\mathrm{N}=120)$

\begin{tabular}{|l|l|l|l|}
\hline \multicolumn{1}{|c|}{ S. No } & \multicolumn{1}{|c|}{ Constraints } & \multicolumn{2}{|c|}{ Farmers score } \\
\hline 1 & Unavailability of improved seed at time of sowing & MPS & Rank \\
\hline 2 & Supply of inferior quality of seed by the input agencies & 79.16 & I \\
\hline 3 & Unavailability of fertilizer at the peak seasons & 54.16 & V \\
\hline 4 & $\begin{array}{l}\text { Requires more organic manure and zypsum for reclamation of } \\
\text { soil }\end{array}$ & 50.83 & III \\
\hline 5 & Unavailability of labour at the time of picking of leaves & 75.00 & IV \\
\hline 6 & $\begin{array}{l}\text { Lack of irrigation facility } \\
\text { Average }\end{array}$ & 39.16 & II \\
\hline
\end{tabular}


Table.3 Financial constraints perceived by the farmer in adoption of Fenugreek cultivation technology $(\mathrm{N}=120)$

\begin{tabular}{|l|l|c|c|}
\hline \multirow{2}{*}{ S. No } & \multicolumn{2}{c|}{ Constraints } & \multicolumn{2}{c|}{ Farmers score } \\
\cline { 3 - 4 } & & MPS & Rank \\
\hline 1 & High cost of inputs & 79.16 & I \\
\hline $\mathbf{2}$ & High charges of electricity & 51.66 & IV \\
\hline 3 & Lack of finance agencies & 66.66 & III \\
\hline 4 & Unavailability of credit on marginal interest & 75.00 & II \\
\hline 5 & Higher charges of labour & 36.66 & V \\
\hline
\end{tabular}

Table.4 Marketing constraints perceived by the respondents in adoption of Fenugreek cultivation technology $(\mathrm{N}=120)$

\begin{tabular}{|l|l|c|c|}
\hline \multicolumn{1}{|c|}{ S. No } & \multicolumn{2}{|c|}{ Constraints } & \multicolumn{2}{c|}{ Farmers score } \\
\hline $\mathbf{1}$ & Lack of regulated market facilities & 91.66 & Rank \\
\hline $\mathbf{2}$ & Incorrect weight measurement by businessman & 36.66 & IX \\
\hline $\mathbf{3}$ & Lack of marketing skill & 70.83 & VI \\
\hline $\mathbf{4}$ & High fluctuation in market prices & 95.83 & II \\
\hline 5 & Minimum support price is not declared by government & 100.00 & I \\
\hline 6 & Unnecessary deduction by businessman & 66.66 & VII \\
\hline 7 & Lack of storage facilities & 93.33 & III \\
\hline $\mathbf{8}$ & Lack of export marketing in the locality & 54.16 & VIII \\
\hline $\mathbf{9}$ & Transportation facilities are very costly & 79.16 & V \\
\hline & Average & $\mathbf{7 6 . 4 8}$ & \\
\hline
\end{tabular}

Table.5 Technical constraints perceived by the respondents in adoption of Fenugreek cultivation technology $(\mathrm{N}=120)$

\begin{tabular}{|l|l|c|c|}
\hline \multicolumn{1}{|c|}{ S. No } & \multicolumn{1}{|c|}{ Constraints } & \multicolumn{2}{|c|}{ Farmers score } \\
\hline $\mathbf{1}$ & Lack of knowledge about recommended seed rate & MPS & Rank \\
\hline $\mathbf{2}$ & Lack of knowledge about processing, grading and standardization & 74.16 & IV \\
\hline $\mathbf{3}$ & Poor knowledge about nutrient management & 58.66 & I \\
\hline $\mathbf{4}$ & Poor knowledge about irrigation management & 36.66 & IX \\
\hline $\mathbf{5}$ & Little knowledge for seed and soil treatment & 75.00 & III \\
\hline $\mathbf{6}$ & Not aware about plant protection chemicals & 62.50 & VI \\
\hline $\mathbf{7}$ & Not convinced about chemical weed control & 56.66 & VIII \\
\hline $\mathbf{8}$ & Lack of knowledge about export quality produce & 65.00 & V \\
\hline $\mathbf{9}$ & Technical guidance unavailable at the time of sowing & 79.16 & II \\
\hline $\mathbf{1 0 .}$ & Lack of training institution & 54.60 & X \\
\hline
\end{tabular}


Table.6 General constraints perceived by the respondents in adoption of Fenugreek cultivation technology $(\mathrm{N}=120)$

\begin{tabular}{|l|l|l|c|}
\hline \multicolumn{1}{|c|}{ S. No } & \multicolumn{1}{|c|}{ Constraints } & \multicolumn{2}{c|}{ Farmers score } \\
\hline $\mathbf{1}$ & Cloudy weather and rainfall at the time of drying of leaves & 80.00 & II \\
\hline $\mathbf{2}$ & Timely unavailability of electricity & 55.83 & V \\
\hline $\mathbf{3}$ & Unavailability of suitable equipment for harvesting of leaves & 91.66 & I \\
\hline $\mathbf{4}$ & Lack of transport facilities & 65.00 & IV \\
\hline $\mathbf{5}$ & More labour requirement during picking of leaves & 70.83 & III \\
\hline $\mathbf{6}$ & Lack of drying facility & 54.16 & VI \\
\hline & Average & $\mathbf{6 9 . 5 8}$ & \\
\hline
\end{tabular}

Table.7 Overall constraints perceived by the respondents in adoption of Fenugreek cultivation technology $(\mathrm{N}=120)$

\begin{tabular}{|l|l|c|c|}
\hline \multirow{2}{*}{ S. No } & \multicolumn{1}{|c|}{ Constraints } & \multicolumn{2}{c|}{ Farmers score } \\
\cline { 3 - 4 } & & MPS & Rank \\
\hline $\mathbf{1}$ & Input constraints & 62.77 & IV \\
\hline $\mathbf{2}$ & Financial constraints & 61.82 & V \\
\hline $\mathbf{3}$ & Marketing constraints & 76.48 & I \\
\hline $\mathbf{4}$ & Technical constraints & 65.62 & III \\
\hline $\mathbf{5}$ & General constraints & 69.58 & II \\
\hline
\end{tabular}

It was also noticed that marketing constraints faced by the respondents data depicted in Table 4 clearly indicates that Minimum support price is not declared by the government(100.00 MPS) was perceived as major constraints and assigned rank first, because the market price of pan methi is fluctuate between Rs 30 to Rs. 130 per $\mathrm{kg}$ during rabi season, so it's essential to declare the minimum support price of this commodity before sowing the crop, Whereas high fluctuation in market prices (95.83 MPS), followed by Lack of storage facilities (93.33 MPS) and Lack of regulated market facilities (91.66 MPS), were also the major constraints faced by the farmers and ranked them at 2 nd, $3 \mathrm{rd}, \& 4$ th place respectively. The another important constraints perceived by the fenugreek growers are Transportation facilities are very costly (79.16 MPS), where upon poor marketing skill (70.83 MPS),
Unnecessary deduction by middle man or businessman (66.66 MPS), Lack of export marketing in the locality (54.16 MPS) and were the important constraints perceived by the growers placed them at $5^{\text {th }}, 6^{\text {th }}, 7^{\text {th }} \& 8^{\text {th }}$ position respectively.

The data evident from Table 5 the views of fenugreek growers about extend of awareness of technical know-how of improved package of practices of fenugreek cultivation. The major difficulty faced by the fenugreek growers in this category was Lack of knowledge about processing grading and standardization with MPS 91.66. Technical guidance unavailable at the time of sowing (79.16 MPS) was another second important problem faced by the fenugreek growers. Whereas little knowledge for seed and soil treatment (75.0MPS) and Lack of knowledge about recommended seed rate (74.16MPS) 
were also important problem faced by the fenugreek growers and ranked them on 3rd and 4th place which states that farmers have little knowledge about seed and soil treatment. Lack of knowledge about export quality produce was ranked on $5^{\text {th }}$ position. Not aware about plant protection measures (62.50MPS) was ranked on 6th position which states that farmers have little information about insect-pest, disease and their control. Poor knowledge about nutrient management (58.33 MPS), Not convinced about chemical weed control (56.66 MPS), more than half of the respondent faced problems due to of training institution (54.60MPS) to provide skill oriented training as awarded last rank.

Further analyzes of Table 6 shows that "Unavailability of suitable equipment for harvesting of leaves" (91.66MPS) and "Cloudy weather and rainfall at the time of drying of leaves" (80.0MPS) were considered most important constraints and ranked at 1st and 2nd place by the fenugreek growers. More labour requirement during picking of leaves and Lack of transport facilities were another important constraint to reverse the adoption process and awarded 3rd and 4th rank respectively.

Further, the overall view clearly indicated that "Marketing constraints" were the most important constraints ranked first which affects the extent of adoption of improved fenugreek cultivation practices in the study area. General constraints i.e. Unavailability of suitable equipment for harvesting of leaves \& Cloudy weather and rainfall at the time of drying of leaves were the second important constraints faced by the fenugreek growers. Marketing constraints i.e. Minimum support price is not declared by government, due to high fluctuation in market prices, Lack of storage facilities, lack of proper market facilities was ranked third by the respondent farmers. Another important constraints was input constraints i.e. unavailability of improved varieties of fenugreek and Unavailability of labour at the time of picking of leaves and ranked at 4th place, whereas Financial constraints i.e. High cost of inputs and Unavailability of credit on marginal interest was least important and placed at 5th position. These finding are in line of Jaitawat et al., (2007), Jat (2008) Sharma et al., (2013), Singh et al., (2013) and Kumar et al., (2016).

Thus from the above explanation it may be concluded that near about half of the majority of the respondent were found to have high adopter of improved fenugreek production technologies. Further concluded that major constraints faced by the farmers in adoption of improved fenugreek technology were Minimum support price is not declared by government, high fluctuation in market prices, lack of storage facilities in the locality, Lack of regulated market facilities, unavailability of technical guidance. In overall the marketing constraints was the major constraint followed by general constraint, technical constraint, input constraint and financial constraints by the fenugreek growers. Therefore, it is suggested that govt take pan methi as major crop of Nagaur district and market price may regulate by govt. and need based training programme should be conducted during crop season to improve the knowledge as well as skill of the fenugreek growers.

\section{References}

Jaitawat G. S., Sisodia S. S. and Bhimawat B. $S$ (2007) Constraints in Adoption of Improved Fennel Cultivation Technology Indian Res. J. Ext. Edu. 7 (2\&3), 52-56

Jat, S.L. (2008) Knowledge and adoption of improved cultivation practices of 
Fenugreek by the farmers of Dantaramgarh tiehsil in Sikar district of Rajasthan, M.Sc (Ag) Thisis (Unpub) SKRAU, Bikaner, campus Jobner.

Kumar, Surendra and Sharma N.K. (2016) Constraints perceived by the farmers in adoption of recommended Coriander production technology Ind. J. Ext. Educ. \& R.D. - Vol. 24: 166-169

Meena, M.L., Chauhan, M.S., Rathore, S. (2002). Adoption and constraints in onion production technology in Alwar district of Rajasthan. Raj. J. Extn. Edu.10:88-92.

Patel. V. T., Prajapati. M. R., Chaudhari. N. V. and Joshi, K. M. (2004). Knowledge and adoption of recommended cumin production technology by the farmers of north Gujarat. Gujarat Journal of Ext. Edu. Vol. 829; 141-145.

Sharma, K. C. and Singh P (2013). Constraints perceived by farmers in adoption of spices production technology in Rajasthan Agriculture Update. Vol. 8(3) 407-411.

Singh. Hari and Jat Jeevan Ram (2013). Impact assessment study in cumin crop in Jodhpur district of Rajasthan. Ind. J. Ext. Edu. \& R. D. Vol. 21: 219-220

Singh. P, Jat. H. L. and Sharma. S.K. (2010). Extent of adoption of clusterbean growers in western zone of Rajasthan. Ind. J. of Agrl. Res. And extension, Vol. 3 II, 49-51.

\section{How to cite this article:}

Kumawat, S.R., U.B. Singh and Bagenia, P.S. 2018. Constraints Pertaining to Fenugreek (Trigonella corniculata) Production Technology in Rajasthan, India. Int.J.Curr.Microbiol.App.Sci. 7(10): 3516-3523. doi: https://doi.org/10.20546/ijcmas.2018.710.406 